Running Head: BASKETBALL JONES

\title{
Basketball jones: Fan passion, motives, and reactions to the suspension of the National Basketball Association season due to COVID-19
}

Benjamin Schellenberg ${ }^{1}$, Jérémie Verner-Filion ${ }^{2}$, Allen Quach $^{1}, \&$ Daniel Bailis $^{3}$

${ }^{1}$ Faculty of Kinesiology and Recreation Management, University of Manitoba.

${ }^{2}$ Département des sciences de L'éducation, Université du Québec en Outaouais

${ }^{3}$ Department of Psychology, University of Manitoba

\section{Acknowledgements}

This is a pre-print of an article that has been accepted for publication in Psychology of Sport and Exercise.

This research was funded in part by the Social Sciences and Humanities Research Council of Canada and in part through the Undergraduate Research Awards program at the University of Manitoba. We thank Sophia Mbabaali for her assistance preparing the online survey. 


\begin{abstract}
The suspension of the 2019-2020 National Basketball Association (NBA) season due to the COVID-19 pandemic meant that NBA fans were unable to engage in an activity that they loved in the midst of a global health crisis. In this research, we assessed if fan responses to the suspension were associated with different types of fan passion and motives. Shortly after the NBA season suspension, NBA fans $(N=395)$ completed online surveys assessing harmonious and obsessive passion for being an NBA fan, motives for watching games, and various attitudes and responses to the suspension. We found that both fan passion and motives predicted responses to the suspension, particularly obsessive passion which predicted greater levels of distress, coping responses, and negative attitudes toward the suspension. These findings have implications for both the passion and fan motives literatures.
\end{abstract}

Keywords: COVID-19; coronavirus; dualistic model of passion; harmonious passion; obsessive passion; sports fans 
On March 11, 2020, the Utah Jazz and Oklahoma City Thunder were scheduled to play in a regular season game for the National Basketball Association (NBA). Moments before tip off, a medical official rushed onto the court to tell the referees, it was later learned, that one of the Jazz players had tested positive for COVID-19. The NBA decided to postpone the game. Later that evening, it announced that it had decided to suspend the entire season (Uggetti, 2020).

The NBA season suspension due to the COVID-19 pandemic meant that basketball fans were unable to watch their favorite teams and players play and did not know when, or even if, the season would resume. This led us to wonder if experiences and responses during the season suspension differed between different types of fans. Specifically, did fans make different stress appraisals and cope differently with the season suspension? Did fans differ in their attitudes and opinions about the decision to suspend the season? More generally, were some fans feeling more stressed during the time of the suspension than others? Our goal in this research was to address these questions by focusing on two fan attributes that we suspected may have predicted different experiences and responses during this unprecedented situation.

First, we expected that the way fans experienced and reacted to the NBA season suspension would be related to their passion for being basketball fans. The dualistic model of passion (Vallerand, 2015) distinguishes between two varieties of passion: harmonious passion (HP) and obsessive passion (OP). Both HP and OP entail loving an activity and incorporating the activity into one's identity. However, they differ in the way in which an activity is internalized. An HP involves an autonomous internalization, which means that one pursues an activity free from any contingencies and with a sense of personal volition. This allows an activity to be pursued with a sense of control and balance, and to become in sync with other parts of a person's identity and life. An OP, however, involves a controlled internalization, which means that one 
feels internal or external pressures to pursue an activity, such as a desire to gain social status or avoid feelings of guilt. To the extent that an activity is pursued with OP, one can feel an uncontrollable urge to pursue the activity, which can come to dominate a person's identity and conflict with other life domains. Over a decade and a half of research in sport (e.g., Vallerand \& Verner-Filion, 2020) and beyond sport (e.g., Curran et al., 2015) has shown that adaptive outcomes are most often positively associated with HP rather than OP.

Both HP and OP have been linked with distinct ways of appraising and coping with stressful situations. With OP, the dominant role that an activity plays in one's identity should cause anything that disrupts activity engagement or obstructs goal progress to be appraised as being stressful and a threat to the self. To cope with these stressors, those with high levels of OP may favor coping strategies oriented toward avoidance and disengagement given that they feel a general lack of control over activity engagement and that the activity is not fully connected with core structures of the self (Schellenberg \& Bailis, 2016). With HP, the balanced role that an activity plays in one's life should diminish the impact of any activity-related disruptions or obstacles and thus lead to fewer stress appraisals. In addition, the sense of personal volition and openness that is characteristic of HP should empower people to cope with stress using active, approach-oriented strategies. Research has supported these tenets by finding that OP predicts greater appraisals of threat and uncontrollability, and more coping effort oriented toward disengagement, whereas HP predicts fewer stress appraisals and more problem-focused coping (e.g. Schellenberg \& Bailis, 2016; Verner-Filion et al., 2014). In fact, research studying the reactions of hockey fans to the 2012 National Hockey League (NHL) lockout - a situation that had many similar features as the 2020 NBA suspension - found that OP for being an NHL fan predicted greater threat appraisals, which in turn predicted greater disengagement-oriented 
coping (Schellenberg et al., 2013). These theoretical and empirical arguments suggest that passion, particularly OP, would predict of how fans reacted to the NBA suspension.

Second, we expected that another fan attribute that would predict reactions to the NBA suspension would be the reasons why fans liked to watch basketball. There are countless reasons why people become sports fans, including a desire to be affiliated with a group, escape life's problems, learn knew things, and feel a sense of fun and excitement (see Wann \& James, 2019). These reasons have been organized into five core motives (Wann \& James, 2019): escape, vicarious achievement, social interaction, aesthetics, and drama. Of these "big five" fan motives, we suspected that people who were fans because it allowed them to escape life problems would have had a particularly difficult time during the season suspension, especially since this meant that they would be unable to use basketball as an escape during a time when there was plenty going on in the world to escape from. Fans who were motivated by the opportunity for social interaction may have also struggled during this time, given the selfisolation and social distancing protocols that were being implemented which would have limited alternative ways of connecting with others. Research studying these five motives is emerging (Wann \& James, 2019), and thus we treated our investigation of the relationship between fan motives and responses to the NBA season suspension as exploratory.

In this research, we considered the season suspension to be a potential stressor for NBA fans and thus focused on fan appraisals and coping, two key elements of the stress process (Lazarus, 1999). We were also interested in how fans reacted to the NBA's decision to suspend the season and their overall level of perceived stress. Although we adopted an exploratory approach to study many of these relationships, including those with all five fan motives, we formed several hypotheses concerning the relationship between passion varieties, appraisals, and 
coping. First, we predicted that OP would be positively associated with stress appraisals (Hypothesis 1) and coping behavior oriented toward disengagement (Hypothesis 2). We also predicted that there would be an indirect effect of OP on disengagement-oriented coping via threat appraisals (Hypothesis 3). HP, on the other hand, was not expected to be strongly related to appraisals or coping behavior. Note that we did not focus on problem-focused coping strategies because we reasoned that fans did not have much power to change the situation they were in (i.e., the NBA suspension). Our three hypotheses were derived from previous research studying the various ways passionate individuals respond to adversity (e.g., Schellenberg \& Bailis, 2016). In fact, we designed our study to be as close as possible to Schellenberg and colleague's (2013) NHL lockout study in order to test if their findings would replicate with the NBA season suspension. In addition to replicating these effects in a situation that was novel and unforeseen, this study was designed to add to our knowledge of sports fandom by exploring if fan responses were predicted by different fan motives, and if either motives or passion predicted attitudes toward the decision to suspend the NBA season due to the COVID-19 pandemic.

\section{Method}

\section{Procedure and Participants}

On March 26, 2020, 15 days after the NBA season was suspended, we distributed online surveys to 395 NBA fans using Prolific Academic. Using G*Power software (Fraul et al., 2009), we calculated that this sample size would allow us to detect a medium-sized effect $(\rho=.2)$ with .95 power and $\alpha=.05$ (two-tailed), while accounting for the removal of participants due to dishonest responding. Four additional Prolific users completed the survey but were excluded from analyses because they reported that they were either not an NBA fan $(n=2)$ or that they responded dishonestly $(n=2)$. Prolific users were eligible to participate if they reported on a pre- 
screening survey that were 18 years of age or older, watched basketball regularly, and lived in the United States. This final criterion was specified because, at the time of the study, COVID-19 rates and public health responses differed greatly between countries.

Participants ranged from 18 to 73 years old $(M=33.42$ years, $S D=11.33$ years $)$, and most identified having a White/European ethnic background (63.8\%) and as being male (76.5\%). Participants reported being an NBA fan for an average of 17.80 years ( $S D=11.18$ years), ranging between 1 and 57 years. Ethics approval was obtained from our university ethics board before this study began, and all participants provided informed consent.

\section{Measures}

Harmonious and obsessive passion. Fans completed the Passion Scale (Vallerand, 2015) to assess levels of HP (e.g., "Being an NBA fan is in harmony with other things that are part of me") and OP (e.g., "I have almost an obsessive feeling for being an NBA fan.") for being an NBA fan on a scale from 1 (not agree at all) to 7 (totally agree). Fans reported how they felt about being an NBA fan during a typical season when games were being played.

Fan motives. Fans answered 15 questions to assess fan motives (see Wann \& James, 2019) on a scale from 1 (not agree at all) to 7 (totally agree). Following the stem "During a typical NBA season, I am motivated to watch NBA games because...”, fans answered questions assessing escape (e.g., “...of the distraction that a game provides from my everyday activities”), vicarious achievement (e.g., “...my favorite team's successes are my successes and their losses are my losses”), social interaction (e.g., “...of the opportunity to interact with other people”), aesthetics (e.g., "...of the natural elegance of the game”), and drama (e.g., “...of the uncertainty 
of a close game") motives. ${ }^{1}$

Appraisals. Fans answered questions from specific subscales of the Stress Appraisal Measure (Peacock \& Wong, 1990) to measure appraisals of the NBA suspension. We targeted scales assessing threat (e.g., "Does the NBA suspension make me feel anxious?"), centrality (e.g., "Does the NBA suspension have important consequences for me?"), and stressfulness (e.g., "Does the NBA suspension create tension in me?") because they appeared to be most relevant to appraisals of the NBA suspension and were also assessed by Schellenberg and colleagues (2013). Items were assessed on a scale from 1 (not at all) to 5 (extremely).

Coping. Fans reported how they were coping with the NBA suspension by answering items from 11 subscales of the brief COPE (Carver, 1997): self-distraction, active coping, denial, emotional support, behavioral disengagement, venting, positive reframing, humour, acceptance, religion, and substance use. We did not assess several other coping strategies that can be measured by the COPE (e.g., planning, self-blame), because they did not appear to be relevant to the NBA suspension and were also not assessed by Schellenberg and colleagues (2013). All items were answered following the stem "To cope with the ongoing NBA season suspension..." using a scale from 1 (I haven't been doing this at all) to 4 (I've been doing this a lot).

Responses to the suspension. We developed a series of questions to assess fan responses to the NBA suspension. These items are reported in the online supplementary file. On a scale ranging from 1 (not agree at all) to 7 (totally agree), fans reported the extent to which they agreed with the decision to suspend the season, monitored and avoided news about the

\footnotetext{
${ }^{1}$ Because this scale is relatively new, we conducted a confirmatory factor analysis to test its factor structure. The results supported the proposed five-factor structure, MLR $\chi^{2}=154.797(d f=80), p<.001$, RMSEA $=.049,90 \% \mathrm{CI}$ $[.037, .060], \mathrm{CFI}=.979, \mathrm{TLI}=.972$.
} 
suspension, worried about the suspension, and engaged in new activities during the suspension. ${ }^{2}$

Perceived stress. General levels of perceived stress were assessed with the 4-item perceived stress scale (Cohen et al., 1983). Following the stem "In the last month..." participants rated how they were feeling (e.g. "...how often have you felt that you were unable to control the important things in your life?") on a scale from 0 (never) to 4 (often).

\section{Results}

We used SPSS (version 25) to screen the data and calculate descriptive statistics and correlations. The online supplementary file reports descriptive statistics, correlations, and internal consistencies. Anonymous data and syntax files are available on the Open Science Framework at https://osf.io/wpszm/.

We assessed relationships between passion varieties and outcomes using partial correlations that controlled for the other passion type (Curran et al., 2015). As shown in Table 1, OP was positively associated with threat, centrality, and stress appraisals (supporting Hypothesis 1), and coping efforts oriented toward disengagement, including denial, venting, and behavioral disengagement (supporting Hypothesis 2), along with seeking emotional support and using religion, and negatively associated with acceptance. OP was also positively associated with avoidance of news and worrying about the NBA suspension, and general levels of perceived stress, and negatively associated with agreement with the NBA suspension. HP was positively associated with all stress appraisals (but to a lesser extent than OP), and with coping efforts aimed at self-distraction, active coping, positive reframing, humour, and acceptance, and negatively associated with behavioral disengagement. HP was also positively associated with

\footnotetext{
${ }^{2}$ We also examined how fans were responding to the COVID-19 pandemic by assessing the extent to which they believed COVID-19 was a serious issue, were engaging in protective behaviors, and worried about COVID-19. These results are presented in the supplementary file because they are not related to the main focus of this research.
} 
agreement with the NBA suspension, monitoring news and worrying about the suspension, engaging in new activities, and negatively associated with avoiding news about the suspension and general levels of perceived stress.

To address Hypothesis 3, we used Mplus (version 8) to analyze a model that tested the mediating effect of threat appraisal in the relationship between passion types and coping (see Figure 1). The model was specified to replicate the model tested by Schellenberg and colleagues (2013); more model details are provided in the supplementary file. The results supported the fit of the model, MLR $\chi^{2}=218.21(d f=94), p<.001, \mathrm{RMSEA}=.058,90 \% \mathrm{CI}[.048, .068], \mathrm{CFI}=$ $.951, \mathrm{TLI}=.938$, and provided evidence of a mediating effect of threat appraisal in the relationship between OP and both disengagement $(\beta=.294, p<.001,95 \%$ CI $[.186, .445])$ and emotion-focused coping $(\beta=.232, p<.001,95 \%$ CI $[.111, .379])$.

Finally, we used correlations to explore relationships between fan motives and responses to the NBA suspension. As shown in Table 1, with a few exceptions, all fan motives tended to show similar associations with stress appraisals, coping, and responses to the NBA suspension. Some relationships that deviated from the overall pattern included a negative association between drama motives and coping using behavioral disengagement and religion, a positive association between drama motives and agreement with the NBA suspension, and positive associations between general perceived stress and both escape and social interaction motives. ${ }^{3}$

\section{Discussion}

\footnotetext{
${ }^{3}$ We also assessed the extent to which fans used substances (alcohol or drugs) to cope with the NBA suspension. However, most fans $(72.9 \%)$ reported never doing so. We therefore categorized fans into those who did or did not use substances at least some of the time to cope with the suspension and used logistic regression to test if the likelihood of using substances to cope was predicted by passion types or fan motives (see Schellenberg et al., 2013). The likelihood of using substances at least a little bit was positively related to OP $(B=0.808, S E=.128, p<.001$, $O R=2.244)$, escape motives $(B=0.395, S E=.083, p<.001, O R=1.48)$, vicarious achievement motives $(B=$ $0.199, S E=.076, p=.009, O R=1.220)$, and social interaction motives $(B=0.241, S E=.074, p=.001, O R=$ 1.272). Substance use was unrelated to HP, aesthetic motives and drama motives.
} 
The 2019-2020 NBA regular season resumed on July 30, 2020, 141 days after being suspended due to the COVID-19 pandemic. For most of the suspension, including when our sample of NBA fans participated in this study, it was unknown when the NBA season would resume, if at all. The results of this study showed that the ways NBA fans responded and felt during this uncertain time was related to both their passion and their motives for being a fan.

This study showed that fans generally felt higher levels of distress during the NBA suspension if they had higher levels of OP. Fans with higher levels of OP appraised the suspension as being more stressful, threatening, and central to their identities, engaged in more coping behaviors, especially those oriented toward disengagement, and tended to avoid news about the suspension. HP, in contrast, predicted stress appraisals and coping to a lesser extent. These findings support previous passion research by showing that, when engagement in an activity is prevented or obstructed, people get more upset and distressed when their passion stems from high OP (e.g., Philippe et al., 2009). They also support the general tendency for OP to predict maladaptive outcomes in sports fans, including rumination, skipping work and family events to watch games, and interpersonal conflict with fans of opposing teams and with romantic partners (Vallerand et al., 2008). These findings also directly replicate the results of Schellenberg and colleagues (2013), who found similar relationships between passion types and fan responses during the 2012-2013 NHL lockout. But this study also adds to our knowledge about passion by showing that HP and OP predict different responses to the source of an activity stoppage - in this case, the decision to suspend the NBA season due to the COVID-19 pandemic. OP predicted less agreement with the decision to suspend the season, whereas HP predicted more agreement. HP also predicted more engagement in new activities during the suspension, a finding the shows how the effects of passion can spill over into other areas of one's life (Vallerand, 2015). 
Fan motives also predicted responses to the NBA suspension, although the results seemed to show that responses were more a function of motive amount rather than motive type. But our exploratory analysis revealed several potential differences between the five fan motives. For instance, compared to the relationships observed with the other fan motives, drama motives was a weaker predictor of stress appraisals, and predicted less use of some coping strategies, and greater agreement with the NBA suspension decision. This suggests that fans who were driven to watch the NBA because of the drama of the game were less distressed by the NBA suspension. Also, general levels of perceived stress were positively associated with escape and social interaction motives. We speculate that this is because the NBA suspension prevented fans from relying on the NBA as an escape from the COVID-19 pandemic, and did not allow fans to use NBA games as an alternative way of connecting with others during a time when social distancing protocols were in place. Research on the big five fan motives is emerging (Wann \& James, 2019), and there is a need for more research to identify the fan experiences that are differentially predicted by different fan motives.

This study is limited by the use of self-report measures, a cross-sectional design, and a sample that may not be representative of the NBA fan population. Future research can build on these findings by studying how fans are reacting to COVID-19 restrictions that are currently in place in many sports leagues, and feeling about additional changes that may need to be implemented in the future (e.g., delayed/truncated seasons, gameplay modifications, attendance restrictions). Additional research can also study how fans respond when professional sports eventually resume in their normal fashion, and if some feel that the disruption to professional sports enhanced their appreciation for sport or even facilitated personal growth in other life areas (e.g., Burke et al., 2012). As the COVID-19 pandemic reminds us, sport is an important part of 
many people's lives, but there are many things that matter much more.

\section{References}

Burke, S.M., Sabiston, C.M., \& Vallerand, R.J. (2012). Passion in breast cancer survivors: Examining links to emotional well-being. Journal of Health Psychology, 17(8), 1161-1175. https://doi.org/fchs

Carver, C.S. (1997). You want to measure coping but your protocol's too long: Consider the Brief COPE. International Journal of Behavioral Medicine, 4(1), 92-100. https://doi.org/d2jv23

Cohen, S., Kamarck, T., \& Mermelstein, R. (1983). A global measure of perceived stress. Journal of Health and Social Behavior, 24(4), 385. https://doi.org/d2wgms

Curran, T., Hill, A.P., Appleton, P.R., Vallerand, R.J., \& Standage, M. (2015). The psychology of passion: A meta-analytical review of a decade of research on intrapersonal outcomes. Motivation and Emotion, 39(5), 631-655. https://doi.org/f7q77b

Faul, F., Erdfelder, E., Buchner, A., \& Lang, A.-G. (2009). Statistical power analyses using G*Power 3.1: Tests for correlation and regression analyses. Behavior Research Methods, 41(4), 1149-1160. https://doi.org/b22kn7

Lazarus, R.S. (1999). Stress and emotion: A new synthesis. Springer.

Peacock, E.J., \& Wong, P.T. (1990). The stress appraisal measure (SAM): A multidimensional approach to cognitive appraisal. Stress Medicine, 6(3), 227-236. https://doi.org/dhxd3s

Philippe, F.L., Vallerand, R.J., Richer, I., Vallières, É., \& Bergeron, J. (2009). Passion for driving and aggressive driving behavior: A look at their relationship: passion and aggressive driving behavior. Journal of Applied Social Psychology, 39(12), 3020-3043. https://doi.org/ddmbxq 
Schellenberg, B.J.I., \& Bailis, D.S. (2016). The two roads of passionate goal pursuit: links with appraisal, coping, and academic achievement. Anxiety, Stress, \& Coping, 29(3), 287-304. https://doi.org/fcht

Schellenberg, B.J.I., Bailis, D.S., \& Crocker, P.R.E. (2013). Passionate hockey fans: Appraisals of, coping with, and attention paid to the 2012-2013 National Hockey League lockout. Psychology of Sport and Exercise, 14(6), 842-846. https://doi.org/f5hrkw

Uggetti, P. (2020, March 11). The NBA has suspended its season after Rudy Gobert's reported positive COVID-19 test. The Ringer. https://tinyurl.com/y4gnv8hl

Vallerand, R.J. (2015). The Psychology of Passion: A Dualistic Model. Oxford University Press. Vallerand, R. J., Ntoumanis, N., Philippe, F. L., Lavigne, G. L., Carbonneau, N., Bonneville, A., Lagacé-Labonté, C., \& Maliha, G. (2008). On passion and sports fans: A look at football. Journal of Sports Sciences, 26(12), 1279-1293. https://doi.org/d5ds5k

Vallerand, R.J., \& Verner-Filion, J. (2020). Theory and research in passion for sport and exercise. In G. Tenenbaum \& R. C. Eklund (Eds.), Handbook of sport psychology $\left(4^{\text {th }}\right.$ ed., pp. 206-229). Wiley \& Sons. https://doi.org/fchv

Verner-Filion, J., Vallerand, R.J., Donahue, É.G., Moreau, É., Martin, A., \& Mageau, G.A. (2014). Passion, coping and anxiety in sport: The interplay between key motivational and self-regulatory processes. International Journal of Sport Psychology, 45(6), 516-537.

Wann, D.L., \& James, J.D. (2019). Sport fans: The psychology and social impact of fandom $\left(2^{\text {nd }}\right.$ edition). Routledge. 


\section{Figure Caption}

Standardized relationships between passion varieties, threat appraisal, and coping.

Coping residuals were allowed to covary (not displayed for clarity). Harmonious and obsessive passion were each modeled with three parcelled indicators. ${ }^{*} p \leq .05, * * p \leq .01$ (two-tailed). 
Table 1

Correlations and partial correlations

\begin{tabular}{|c|c|c|c|c|c|c|c|}
\hline & \multicolumn{2}{|c|}{ Passion } & \multicolumn{5}{|c|}{ Motives } \\
\hline & $\mathrm{HP}$ & $\mathrm{OP}$ & ESCAPE & SOCIAL & VICACH & AES & DRAMA \\
\hline \multicolumn{8}{|l|}{ Stress Appraisals } \\
\hline Threat & $\begin{array}{c}.168 * * \\
{[.063, .271]}\end{array}$ & $\begin{array}{c}.406 * * \\
{[.306, .498]}\end{array}$ & $\begin{array}{c}.370 * * \\
{[278, .452]}\end{array}$ & $\begin{array}{c}.346^{* *} \\
{[.256, .431]}\end{array}$ & $\begin{array}{c}.405^{* *} \\
{[.325, .479]}\end{array}$ & $\begin{array}{c}.266 * * \\
{[.173, .357]}\end{array}$ & $\begin{array}{c}.145 * * \\
{[.046, .241]}\end{array}$ \\
\hline Centrality & $\begin{array}{c}.145^{* *} * \\
{[.039, .249]}\end{array}$ & $\begin{array}{c}.467 * * \\
{[.364, .562]}\end{array}$ & $\begin{array}{c}.325^{* *} \\
{[.235, .407]}\end{array}$ & $\begin{array}{c}.318^{* *} \\
{[.226, .402]}\end{array}$ & $\begin{array}{c}.377 * * \\
{[.300, .448]}\end{array}$ & $\begin{array}{c}.278 * * \\
{[.185, .364]}\end{array}$ & $\begin{array}{c}.054 \\
{[-.041, .146]}\end{array}$ \\
\hline Stressfulness & $\begin{array}{c}.133 * * \\
{[.031, .229]}\end{array}$ & $\begin{array}{c}.488 * * \\
{[.402, .569]}\end{array}$ & $\begin{array}{c}.383 * * \\
{[.298, .463]}\end{array}$ & $\begin{array}{c}.306 * * \\
{[.215, .392]}\end{array}$ & $\begin{array}{c}.405^{* *} \\
{[.328, .477]}\end{array}$ & $\begin{array}{c}.268 * * \\
{[.172, .355]}\end{array}$ & $\begin{array}{c}.135^{* *} \\
{[.039, .227]}\end{array}$ \\
\hline \multicolumn{8}{|l|}{ Coping } \\
\hline Self-Distraction & $\begin{array}{c}.291 * * \\
{[.195, .384]}\end{array}$ & $\begin{array}{c}-.022 \\
{[-.128, .081]}\end{array}$ & $\begin{array}{c}.349 * * \\
{[.248, .441]}\end{array}$ & $\begin{array}{c}.247 * * \\
{[.134, .357]}\end{array}$ & $\begin{array}{c}.358^{* *} \\
{[.264, .447]}\end{array}$ & $\begin{array}{c}.286 * * \\
{[.187, .379]}\end{array}$ & $\begin{array}{c}.239 * * \\
{[.137, .338]}\end{array}$ \\
\hline Active Coping & $\begin{array}{c}.191 * * \\
{[.086, .292]}\end{array}$ & $\begin{array}{c}.041 \\
{[-.052, .136]}\end{array}$ & $\begin{array}{c}.293^{* *} \\
{[.184 . .388]}\end{array}$ & $\begin{array}{c}.308^{* *} \\
{[.202, .410]}\end{array}$ & $\begin{array}{c}.286^{* *} \\
{[.182, .386] .}\end{array}$ & $\begin{array}{c}.328 * * \\
{[.231, .423]}\end{array}$ & $\begin{array}{c}.204 * * \\
{[.108, .298]}\end{array}$ \\
\hline Denial & $\begin{array}{c}-.071 \\
{[-.168, .023]}\end{array}$ & $\begin{array}{c}.455^{* *} \\
{[.356, .547]}\end{array}$ & $\begin{array}{c}.267 * * \\
{[.175,353]}\end{array}$ & $\begin{array}{c}.182 * * \\
{[.089, .271]}\end{array}$ & $\begin{array}{c}.199 * * \\
{[.101, .294]}\end{array}$ & $\begin{array}{c}.132 * * \\
{[.028, .228]}\end{array}$ & $\begin{array}{c}-.019 \\
{[-.112, .076]}\end{array}$ \\
\hline Emotional Support & $\begin{array}{c}.053 \\
{[-.047, .149]}\end{array}$ & $\begin{array}{c}.286 * * \\
{[.194, .375]}\end{array}$ & $\begin{array}{c}.239 * * \\
{[.137, .332]}\end{array}$ & $\begin{array}{c}.305^{* *} \\
{[.196, .405]}\end{array}$ & $\begin{array}{c}.207 * * \\
{[.114, .298]}\end{array}$ & $\begin{array}{c}.138 * * \\
{[.034, .233]}\end{array}$ & $\begin{array}{c}.035 \\
{[-.072, .136]}\end{array}$ \\
\hline $\begin{array}{l}\text { Behavioral } \\
\text { Disengagement }\end{array}$ & $\begin{array}{c}-.166 * * \\
{[-.245,-.085]}\end{array}$ & $\begin{array}{c}.513 * * \\
{[.420, .599]}\end{array}$ & $\begin{array}{c}.176 * * \\
{[.076, .272]}\end{array}$ & $\begin{array}{c}.184 * * \\
{[.088, .274]}\end{array}$ & $\begin{array}{c}.153 * * \\
{[.060, .240]}\end{array}$ & $\begin{array}{c}.030 \\
{[-.060, .114]}\end{array}$ & $\begin{array}{c}-.130 * * \\
{[-.243,-.020]}\end{array}$ \\
\hline Venting & $\begin{array}{c}.065 \\
{[-.031, .158]}\end{array}$ & $\begin{array}{c}.315^{* *} \\
{[.209, .420]}\end{array}$ & $\begin{array}{c}.325^{* *} \\
{[.231, .413]}\end{array}$ & $\begin{array}{c}.262 * * \\
{[.170, .348]}\end{array}$ & $\begin{array}{c}.351 * * \\
{[.271, .427]}\end{array}$ & $\begin{array}{c}.151 * * \\
{[.053, .245]}\end{array}$ & $\begin{array}{c}.107 * \\
{[.012, .192]}\end{array}$ \\
\hline Positive Reframing & $\begin{array}{c}.203 * * \\
{[.108, .295]}\end{array}$ & $\begin{array}{c}.058 \\
{[-.042, .157]}\end{array}$ & $\begin{array}{c}.266^{* *} \\
{[.164, .359]}\end{array}$ & $\begin{array}{c}.287 * * \\
{[.186, .386]}\end{array}$ & $\begin{array}{c}.304 * * \\
{[.209, .392]}\end{array}$ & $\begin{array}{c}.190 * * \\
{[.084, .295]}\end{array}$ & $\begin{array}{c}.206 * * \\
{[.110, .297]}\end{array}$ \\
\hline Humour & $\begin{array}{c}.140 * * \\
{[.045, .229]}\end{array}$ & $\begin{array}{c}.059 \\
{[-.039, .157]}\end{array}$ & $\begin{array}{c}.203 * * \\
{[.099, .304]}\end{array}$ & $\begin{array}{c}.294 * * \\
{[.198, .384]}\end{array}$ & $\begin{array}{c}.220 * * \\
{[.123, .308]}\end{array}$ & $\begin{array}{c}.147 * * \\
{[.040, .250]}\end{array}$ & $\begin{array}{c}.270 * * \\
{[.177, .360]}\end{array}$ \\
\hline Acceptance & $\begin{array}{c}.203 * * \\
{[.094, .304]}\end{array}$ & $\begin{array}{c}-.214 * * \\
{[-.313,-.116]}\end{array}$ & $\begin{array}{c}.066 \\
{[-.042, .173]}\end{array}$ & $\begin{array}{c}.115^{*} \\
{[.011, .213]}\end{array}$ & $\begin{array}{c}.129 * * \\
{[.030, .229]}\end{array}$ & $\begin{array}{c}.131 * * \\
{[.023, .235]}\end{array}$ & $\begin{array}{c}.212 * * \\
{[.113, .310]}\end{array}$ \\
\hline Religion & $\begin{array}{c}-.046 \\
{[-.151, .060]}\end{array}$ & $\begin{array}{c}.257 * * \\
{[.152, .358]}\end{array}$ & $\begin{array}{c}.183^{* *} \\
{[.083,281]}\end{array}$ & $\begin{array}{c}.215^{* *} \\
{[.117, .307]}\end{array}$ & $\begin{array}{c}.142 * * \\
{[.032, .249]}\end{array}$ & $\begin{array}{c}.144 * * \\
{[.046, .243]}\end{array}$ & $\begin{array}{c}-.134 * * \\
{[-.233,-.038]}\end{array}$ \\
\hline \multicolumn{8}{|c|}{ Response to NBA suspension } \\
\hline $\begin{array}{l}\text { Agreement with } \\
\text { suspension }\end{array}$ & $\begin{array}{c}.150 * * \\
{[.051, .248]}\end{array}$ & $\begin{array}{c}-.188^{* *} \\
{[-.291,-.083]}\end{array}$ & $\begin{array}{c}-.061 \\
{[-.160, .038]}\end{array}$ & $\begin{array}{c}.043 \\
{[-.058, .148]}\end{array}$ & $\begin{array}{c}-.048 \\
{[-.146, .056]}\end{array}$ & $\begin{array}{c}.066 \\
{[-.035, .173]}\end{array}$ & $\begin{array}{c}.160 * * \\
{[.051, .270]}\end{array}$ \\
\hline Monitoring News & $\begin{array}{c}.378^{* *} \\
{[.283, .469]}\end{array}$ & $\begin{array}{c}-.006 \\
{[-.097, .082]}\end{array}$ & $\begin{array}{c}.286^{* *} \\
{[.184, .383]}\end{array}$ & $\begin{array}{c}.306^{* *} \\
{[.196, .412]}\end{array}$ & $\begin{array}{c}.406 * * \\
{[.304, .500]}\end{array}$ & $\begin{array}{c}.410 * * \\
{[.309, .505]}\end{array}$ & $\begin{array}{c}.257 * * \\
{[.158, .352]}\end{array}$ \\
\hline Avoiding News & $\begin{array}{c}-.189 * * \\
{[-.284,-.092]}\end{array}$ & $\begin{array}{c}.348 * * \\
{[.239, .450]}\end{array}$ & $\begin{array}{c}.074 \\
{[-.029, .178]}\end{array}$ & $\begin{array}{c}.103 * \\
{[-.001, .203]}\end{array}$ & $\begin{array}{c}-.024 \\
{[-.126, .077]}\end{array}$ & $\begin{array}{c}-.049 \\
{[-.149, .050]}\end{array}$ & $\begin{array}{c}-.094 \\
{[-.199, .007]}\end{array}$ \\
\hline Suspension Worry & $\begin{array}{c}.200 * * \\
{[.102, .299]}\end{array}$ & $\begin{array}{c}.351^{* *} \\
{[.244, .449]}\end{array}$ & $\begin{array}{c}.408^{* *} \\
{[.320, .491]}\end{array}$ & $\begin{array}{c}.290 * * \\
{[.196, .381]}\end{array}$ & $\begin{array}{c}.452 * * \\
{[.371, .526]}\end{array}$ & $\begin{array}{c}.282 * * \\
{[.191, .370]}\end{array}$ & $\begin{array}{c}.171 * * \\
{[.077, .260]}\end{array}$ \\
\hline New activities & $\begin{array}{c}.247 * * \\
{[.152, .340]}\end{array}$ & $\begin{array}{c}.031 \\
{[-.065, .125]}\end{array}$ & $\begin{array}{c}.338 * \\
{[.237, .435]}\end{array}$ & $\begin{array}{c}.283 * * \\
{[.181, .382]}\end{array}$ & $\begin{array}{c}.264 * * \\
{[.165, .360]}\end{array}$ & $\begin{array}{c}.260 * * \\
{[.157, .360]}\end{array}$ & $\begin{array}{c}.239 * * \\
{[.141, .334]}\end{array}$ \\
\hline Perceived Stress & $\begin{array}{c}-.108 * \\
{[-.216,-.001]}\end{array}$ & $\begin{array}{c}.223 * * \\
{[.125, .317]}\end{array}$ & $\begin{array}{c}.238 * * \\
{[.134, .335]}\end{array}$ & $\begin{array}{c}.167 * * \\
{[.058, .273]}\end{array}$ & $\begin{array}{c}.057 \\
{[-.041, .154]}\end{array}$ & $\begin{array}{c}-.056 \\
{[-.159, .047]}\end{array}$ & $\begin{array}{c}-.039 \\
{[-.135, .056]}\end{array}$ \\
\hline
\end{tabular}

Note. $N=395$. Partial correlations are presented with passion types (controlling for the other passion type). Correlations are presented with fan motives. Confidence intervals reported in brackets are bias-corrected and based on 5,000 bootstrap samples. $\mathrm{HP}=$ harmonious passion. $\mathrm{OP}=$ obsessive passion. SOCIAL $=$ social interaction. $\mathrm{VICACH}=$ vicarious achievement. AES $=$ aesthetics. ${ }^{*} p \leq .05,{ }^{*} p \leq .01$ (two-tailed). 


\section{Figure 1}

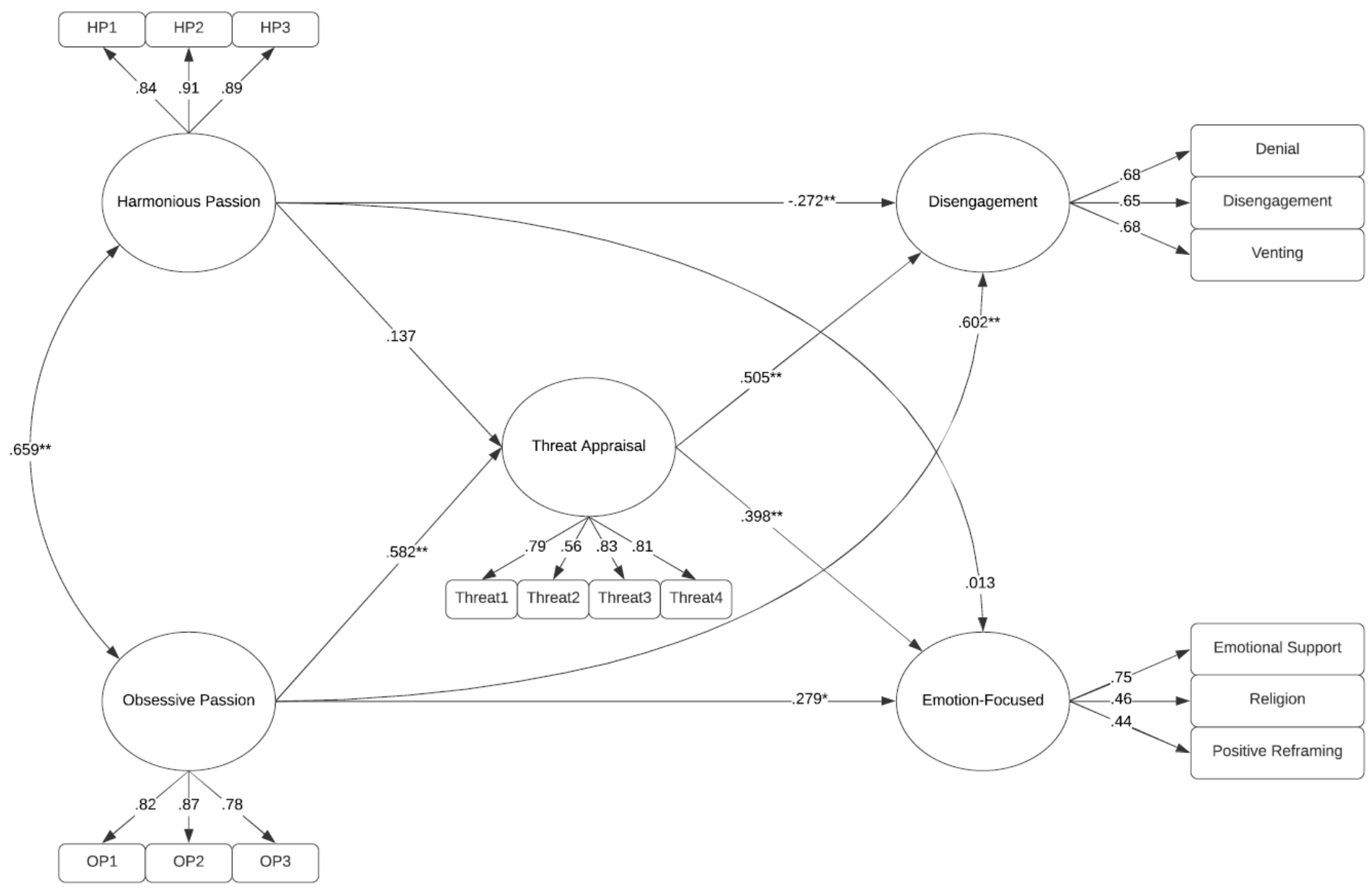




\section{Supplementary File}

Table S1

Descriptive statistics

\begin{tabular}{|c|c|c|c|}
\hline & $\omega$ & $M$ & $S D$ \\
\hline \multicolumn{4}{|l|}{ Passion } \\
\hline Harmonious Passion & .90 & 4.24 & 1.27 \\
\hline Obsessive Passion & .88 & 2.28 & 1.25 \\
\hline \multicolumn{4}{|l|}{ Fan Motives } \\
\hline Escape & .93 & 4.11 & 1.52 \\
\hline Social Interaction & .95 & 4.08 & 1.62 \\
\hline Vicarious Achievement & .91 & 4.48 & 1.57 \\
\hline Aesthetics & .94 & 4.58 & 1.53 \\
\hline Drama & .83 & 5.54 & 1.19 \\
\hline \multicolumn{4}{|l|}{ Stress Appraisals } \\
\hline Threat & .84 & 2.19 & 0.93 \\
\hline Centrality & .88 & 1.87 & 0.88 \\
\hline Stressfulness & .86 & 2.02 & 0.92 \\
\hline \multicolumn{4}{|l|}{ Coping } \\
\hline Self-Distraction & --- & 2.73 & 0.80 \\
\hline Active Coping & --- & 2.50 & 0.78 \\
\hline Denial & --- & 1.53 & 0.79 \\
\hline Emotional Support & --- & 1.87 & 0.81 \\
\hline Behavioral Disengagement & --- & 1.44 & 0.67 \\
\hline Venting & --- & 1.76 & 0.74 \\
\hline Positive Reframing & --- & 2.33 & 0.83 \\
\hline Humour & --- & 2.18 & 0.94 \\
\hline Acceptance & --- & 3.03 & 0.76 \\
\hline Religion & --- & 1.71 & 0.94 \\
\hline \multicolumn{4}{|l|}{ Response to NBA suspension } \\
\hline Agreement with suspension & .72 & 5.33 & 1.22 \\
\hline Monitoring News & .90 & 4.85 & 1.50 \\
\hline Avoiding News & .74 & 2.19 & 1.29 \\
\hline Worrying about suspension & .82 & 3.13 & 1.50 \\
\hline Pursuing new activities & .82 & 4.09 & 1.47 \\
\hline \multicolumn{4}{|l|}{ Response to COVID-19 } \\
\hline Seriousness of COVID-19 & .88 & 5.80 & 1.45 \\
\hline Behavioral Responding & .88 & 5.99 & 1.18 \\
\hline Worrying about COVID-19 & .89 & 3.98 & 1.70 \\
\hline Perceived Stress & .73 & 1.63 & 0.77 \\
\hline
\end{tabular}

Note. $N=395$. McDonald's omega $(\omega)$ is reported as an indicator of internal consistency. 
Table S2

Correlations

\begin{tabular}{|c|c|c|c|c|c|c|c|c|c|c|c|c|c|c|}
\hline & 1 & 2 & 3 & 4 & 5 & 6 & 7 & 8 & 9 & 10 & 11 & 12 & 13 & 14 \\
\hline \multicolumn{15}{|l|}{ 1. HP } \\
\hline 2. $\mathrm{OP}$ & $.59 * *$ & & & & & & & & & & & & & \\
\hline 3. ESCAPE & $.38 * *$ & $.38 * *$ & & & & & & & & & & & & \\
\hline 4. SOCIAL & $.51 * *$ & $.39 * *$ & $.37 * *$ & & & & & & & & & & & \\
\hline 5. VICACH & $.61 * *$ & $.45^{* *}$ & $.44 * *$ & $.43 * *$ & & & & & & & & & & \\
\hline 6. AES & $.55^{* *}$ & $.35^{* *}$ & $.26^{* *}$ & $.43 * *$ & $.42 * *$ & & & & & & & & & \\
\hline 7. DRAMA & $.41 * *$ & $.11 * *$ & $.30 * *$ & $.29 * *$ & $.38 * *$ & $.47 * *$ & & & & & & & & \\
\hline 8. THREAT & $.44 * *$ & $.56 * *$ & $.37 * *$ & $.35 * *$ & $.41 * *$ & $.27 * *$ & $.15^{* *}$ & & & & & & & \\
\hline 9. CENTRAL & $.45^{* *}$ & $.60 * *$ & $.33 * *$ & $.32 * *$ & $.38 * *$ & $.28 * *$ & .05 & $.81 * *$ & & & & & & \\
\hline 10. STRESS & $.45 * *$ & $.62 * *$ & $.38 * *$ & $.31 * *$ & $.41 * *$ & $.27 * *$ & $.14 * *$ & $.85 * *$ & $.84 * *$ & & & & & \\
\hline 11. DISTRACT & $.34 * *$ & $.19 * *$ & $.35^{* *}$ & $.25 * *$ & $.36 * *$ & $.29 * *$ & $.24 * *$ & $.26 * *$ & $.23 * *$ & $.28 * *$ & & & & \\
\hline 12. ACTIVE & $.26 * *$ & $.19 * *$ & $.29 * *$ & $.31 * *$ & $.29 * *$ & $.33 * *$ & $.20 * *$ & $.23 * *$ & $.22 * *$ & $.26 * *$ & $.56 * *$ & & & \\
\hline 13. DENIAL & $.25 * *$ & $.50 * *$ & $.27 * *$ & $.18 * *$ & $.20 * *$ & $.13 * *$ & -.02 & $.46^{* *}$ & $.52 * *$ & $.55 * *$ & $.15^{* *}$ & $.23 * *$ & & \\
\hline 14. EMOTION & $.26 * *$ & $.38 * *$ & $.24 * *$ & $.31 * *$ & $.21 * *$ & $.14 * *$ & .04 & $.38 * *$ & $.42 * *$ & $.39 * *$ & $.34 * *$ & $.37 * *$ & $.44 * *$ & \\
\hline 15. DISENG & $.20 * *$ & $.52 * *$ & $.18 * *$ & $.18 * *$ & $.15 * *$ & .03 & $-.13 * *$ & $.43 * *$ & $.50 * *$ & $.45^{* *}$ & .08 & .10 & $.47 * *$ & $.40 * *$ \\
\hline 16. VENT & $.30 * *$ & $.42 * *$ & $.33 * *$ & $.26 * *$ & $.35 * *$ & $.15^{* *}$ & $.11 *$ & $.49 * *$ & $.47 * *$ & $.51 * *$ & $.26 * *$ & $.30 * *$ & $.47 * *$ & $.57 * *$ \\
\hline 17. REFRAME & $.29 * *$ & $.22 * *$ & $.27 * *$ & $.29 * *$ & $.30 * *$ & $.19 * *$ & $.21 * *$ & $.26 * *$ & $.25 * *$ & $.27 * *$ & $.47 * *$ & $.41 * *$ & $.19 * *$ & $.34 * *$ \\
\hline 18. HUMOUR & $.21 * *$ & $.17 * *$ & $.20 * *$ & $.29 * *$ & $.22 * *$ & $.15^{* *}$ & $.27 * *$ & $.24 * *$ & $.19 * *$ & $.23 * *$ & $.18^{* *}$ & $.12 *$ & $.16^{* *}$ & $.18^{*}$ \\
\hline 19. ACCEPT & .09 & $-.12 *$ & .07 & $.12 *$ & $.13 * *$ & $.13^{* *}$ & $.21 * *$ & $-.10^{*}$ & $-.14 * *$ & $-.15 * *$ & $.33 * *$ & $.22 * *$ & $-.22 * *$ & .00 \\
\hline 20. RELIG & $.13 * *$ & $.28 * *$ & $.18^{* *}$ & $.22 * *$ & $.14 * *$ & $.14 * *$ & $-.13 * *$ & $.24 * *$ & $.33 * *$ & $.26 * *$ & $.19 * *$ & $.26 * *$ & $.31 * *$ & $.30 * *$ \\
\hline 21. AGREE & .05 & $-.12 *$ & -.06 & .04 & -.05 & .07 & $.16^{* *}$ & $-.23 * *$ & $-.25 * *$ & $-.21 * *$ & .07 & $.14 * *$ & $-.20 * *$ & -.01 \\
\hline 22. MONITOR & $.45 * *$ & $.26 * *$ & $.29 * *$ & $.31 * *$ & $.41 * *$ & $.41 * *$ & $.26 * *$ & $.29 * *$ & $.27 * *$ & $.29 * *$ & $.36^{* *}$ & $.36 * *$ & $.12 *$ & $.19 * *$ \\
\hline 23. AVOID & .03 & $.30 * *$ & .07 & $.10^{*}$ & -.02 & -.05 & -.09 & .08 & $.14 * *$ & $.11^{*}$ & -.09 & -.01 & $.16^{* *}$ & $.14 * *$ \\
\hline 24. NBA WORRY & $.45 * *$ & $.52 * *$ & $.41^{* *}$ & $.29 * *$ & $.45^{* *}$ & $.28 * *$ & $.17 * *$ & $.72 * *$ & $.68 * *$ & $.71 * *$ & $.29 * *$ & $.29 * *$ & $.44 * *$ & $.39 * *$ \\
\hline 25. NEWACT & $.32 * *$ & $.21 * *$ & $.34 * *$ & $.28 * *$ & $.26 * *$ & $.26 * *$ & $.24 * *$ & $.27 * *$ & $.24 * *$ & $.28 * *$ & $.49 * *$ & $.41 * *$ & $.19 * *$ & $.24 * *$ \\
\hline 26. SERIOUS & -.07 & $-.25 * *$ & -.04 & -.06 & $-.12 *$ & -.02 & .08 & $-.22 * *$ & $-.27 * *$ & $-.24 * *$ & .06 & .04 & $-.21 * *$ & -.07 \\
\hline 27. RESPOND & $.11^{*}$ & $-.11 *$ & $.13 * *$ & $.13^{*}$ & $.17 * *$ & $.12 *$ & $.22 * *$ & -.07 & $-.10 *$ & -.09 & $.13 *$ & $.11 *$ & $-.13 * *$ & -.02 \\
\hline 28. COVID WORRY & $.10 *$ & $.22 * *$ & $.27 * *$ & .09 & $.14 * *$ & .03 & -.03 & $.26 * *$ & $.25^{* *}$ & $.27 * *$ & $.12 *$ & $.13^{*}$ & $.16^{* *}$ & $.26 * *$ \\
\hline 29. PS & .03 & $.20 * *$ & $.24 * *$ & $.17 * *$ & .06 & -.06 & -.04 & $.25 * *$ & $.22 * *$ & $.26 * *$ & .08 & $.11 *$ & $.29 * *$ & $.27 * *$ \\
\hline
\end{tabular}

Note. $N=395 . \mathrm{HP}=$ harmonious passion. $\mathrm{OP}=$ obsessive passion. $\mathrm{SOCIAL}=$ social interaction. $\mathrm{VICACH}=$ vicarious achievement. AES $=$ aesthetics

THREAT $=$ threat appraisal. CENTRAL $=$ centrality appraisal. STRESS $=$ stress appraisal. DISTRACT $=$ self-distraction. ACTIVE $=$ active coping.

EMOTION $=$ emotional support. DISENG $=$ behavioral disengagement. VENT $=$ venting. REFRAME $=$ positive reframing. ACCEPT $=$ acceptance. RELIG $=$ religion. AGREE $=$ agreement with NBA suspension. MONITOR $=$ monitoring news. AVOID $=$ avoiding news. NBA worry $=$ worrying about suspension.

NEWACT $=$ pursuing new activities. SERIOUS $=$ seriousness of COVID-19. RESPOND $=$ behavioral responding to COVID-19. COVID WORRY $=$ worrying about COVID-19. PS $=$ perceived stress $* p \leq .05 * * x \leq .01$ 
Table S2 (continued)

Correlations

\begin{tabular}{|c|c|c|c|c|c|c|c|c|c|c|c|c|c|c|}
\hline & 15 & 16 & 17 & 18 & 19 & 20 & 21 & 22 & 23 & 24 & 25 & 26 & 27 & 28 \\
\hline \multicolumn{15}{|l|}{ 1. HP } \\
\hline \multicolumn{15}{|l|}{ 2. OP } \\
\hline \multicolumn{15}{|l|}{ 3. ESCAPE } \\
\hline \multicolumn{15}{|l|}{ 4. SOCIAL } \\
\hline \multicolumn{15}{|l|}{ 5. VICACH } \\
\hline \multicolumn{15}{|l|}{ 6. AES } \\
\hline \multicolumn{15}{|l|}{ 7. DRAMA } \\
\hline \multicolumn{15}{|l|}{ 8. THREAT } \\
\hline \multicolumn{15}{|l|}{ 9. CENTRAL } \\
\hline \multicolumn{15}{|l|}{ 10. STRESS } \\
\hline \multicolumn{15}{|l|}{ 11. DISTRACT } \\
\hline \multicolumn{15}{|l|}{ 12. ACTIVE } \\
\hline \multicolumn{15}{|l|}{ 13. DENIAL } \\
\hline \multicolumn{15}{|l|}{ 14. EMOTION } \\
\hline \multicolumn{15}{|l|}{ 15. DISENG } \\
\hline 16. VENT & $.41 * *$ & & & & & & & & & & & & & \\
\hline 17. REFRAME & $.18^{* *}$ & $.25 * *$ & & & & & & & & & & & & \\
\hline 18. HUMOUR & $.19^{* *}$ & $.27 *$ & $.28 * *$ & & & & & & & & & & & \\
\hline 19. АCСЕРT & -.06 & .02 & $.28 * *$ & $.20 * *$ & & & & & & & & & & \\
\hline 20. RELIG & $.28 * *$ & $.30 * *$ & $.33^{* *}$ & .05 & .02 & & & & & & & & & \\
\hline 21. AGREE & $-.11 *$ & $-.11 *$ & .09 & .00 & $.29 * *$ & -.05 & & & & & & & & \\
\hline 22. MONITOR & .04 & $.23 * *$ & $.24 * *$ & .09 & $.16^{* *}$ & $.11^{*}$ & $.20 * *$ & & & & & & & \\
\hline 23. AVOID & $.31 * *$ & $.18 * *$ & .03 & $.10^{*}$ & $-.14 * *$ & $.14 * *$ & -.04 & $-.31 * *$ & & & & & & \\
\hline 24. NBA WORRY & $.40 * *$ & $.55^{* *}$ & $.28 * *$ & $.22 * *$ & $-.11 *$ & $.24 * *$ & $-.21 * *$ & $.35 * *$ & $.14 * *$ & & & & & \\
\hline 25. NEWACT & $.12^{*}$ & $.27 * *$ & $.45^{* *}$ & $.24 * *$ & $.23 * *$ & $.23 * *$ & $.12 *$ & $.32 * *$ & .08 & $.33 * *$ & & & & \\
\hline 26. SERIOUS & $-.19 * *$ & $-.14 * *$ & .04 & $-.13^{*}$ & $.19 * *$ & $-.12 *$ & $.45^{* *}$ & $.12^{*}$ & $-.27 * *$ & $-.19 * *$ & -.07 & & & \\
\hline 27. RESPOND & $-.15 * *$ & -.09 & $.11 *$ & -.07 & $.21 * *$ & .01 & $.42 * *$ & $.27 * *$ & $-.15^{* *}$ & -.04 & $.11^{*}$ & $.39 * *$ & & \\
\hline 28. COVID WORRY & $.24 * *$ & $.24 * *$ & $.18^{* *}$ & .03 & -.03 & $.13 *$ & $.23 * *$ & $.16^{* *}$ & .09 & $.36 * *$ & .09 & $.24 * *$ & $.28 * *$ & \\
\hline 29. PS & $.31 * *$ & $.26 * *$ & .08 & .07 & $-.12 *$ & $.23^{* *}$ & .02 & -.05 & .10 & $.24 * *$ & .03 & .03 & -.06 & $.42 * *$ \\
\hline
\end{tabular}

Note. $N=395$. HP = harmonious passion. $\mathrm{OP}=$ obsessive passion. SOCIAL $=$ social interaction. $\mathrm{VICACH}=$ vicarious achievement. AES $=$ aesthetics

THREAT $=$ threat appraisal. CENTRAL $=$ centrality appraisal. STRESS $=$ stress appraisal. DISTRACT $=$ self-distraction. ACTIVE $=$ active coping.

EMOTION $=$ emotional support. DISENG $=$ behavioral disengagement. VENT $=$ venting. REFRAME $=$ positive reframing. ACCEPT $=$ acceptance. RELIG $=$ religion. AGREE = agreement with NBA suspension. MONITOR = monitoring news. AVOID = avoiding news. NBA worry = worrying about suspension.

NEWACT = pursuing new activities. SERIOUS = seriousness of COVID-19. RESPOND = behavioral responding to COVID-19. COVID WORRY = worrying about COVID-19. PS $=$ perceived stress $* p \leq .05 * * p \leq .01$ 


\section{Table S3}

Correlations between latent variables and composite reliabilities

\begin{tabular}{|c|c|c|c|c|c|}
\hline & 1 & 2 & 3 & 4 & 5 \\
\hline 1. HP & .913 & & & & \\
\hline 2. OP & $.659 * *$ & .861 & & & \\
\hline 3. Threat Appraisal & $.521 * *$ & $.673 * *$ & .837 & & \\
\hline 4. Disengagement Coping & $.387 * *$ & $.762 * *$ & $.768 * *$ & .709 & \\
\hline 5. Emotion-Focused Coping & $.404 * *$ & $.555^{* *}$ & $.593 * *$ & $.910 * *$ & .575 \\
\hline
\end{tabular}

Note. $N=395$. $\mathrm{HP}=$ harmonious passion. $\mathrm{OP}=$ obsessive passion. Composite reliabilities are reported on the diagonal.

$* p \leq .05 * * p \leq .01$ 


\section{Table S4}

Items assessing responses to the NBA suspension and COVID-19 pandemic

\section{Subscales}

\section{Responses to NBA suspension}

Agreement with 1. It was a smart decision to suspend the NBA season due to the COVID-19 outbreak.

suspension

2. The NBA season needed to be suspended due to the COVID-19 outbreak.

3. The NBA season should have been suspended earlier.

Monitoring news 1. I have been actively following the news coverage of the NBA suspension.

2. When new information regarding the suspension is available, I am interesting in learning about it.

3. I have been watching the news, reading the newspaper, and/or going online to learn more about the NBA suspension.

Avoiding news 1. I haven't been interested in learning about news of the NBA suspension.

2. When information about the NBA season suspension is in the news, I try not to pay attention to it.

3. I haven't been paying attention to the specific details of the NBA season suspension.

Suspension worry 1. I am worried that the NBA season will not resume this year.

2. Thinking about the current NBA season suspension makes me feel upset and anxious.

3. I often worry about the NBA season suspension.

New activities $\quad 1$. Now that the NBA season has been suspended, I have been trying out different activities during my spare time.

2. Now that the NBA season has been suspended, I have been searching for a new hobby to pursue.

3. The NBA season suspension is a great opportunity to adopt a new skill, hobby, or pastime.

\section{Responses to COVID-19}

Seriousness

1. I believe the COVID-19 outbreak is a serious issue for the world.

2. I believe people are overreacting to COVID-19. (R)

3. I think the media is making COVID-19 a bigger deal than it actually should be. (R)

Behavioral 1. I have been taking extra precautions, including increased hand washing/sanitizing and social distancing, to protect

responding myself against COVID-19.

2. I have been following the recommendations provided by the government and medical experts to protect myself against COVID-19.

3. I have been doing everything that I can to reduce my chances of being exposed to COVID-19.

COVID-19 worry 1. I am worried that I will be exposed to COVID-19.

2. Thinking about COVID-19 makes me feel upset and anxious.

3. I often worry about COVID-19.

Note. Each item was assessed on a scale from 1 (not agree at all) to 7 (totally agree). (R) indicates items that were reversed scored. 
Table S5

Additional correlations and partial correlations

\begin{tabular}{|c|c|c|c|c|c|c|c|}
\hline & \multicolumn{2}{|c|}{ Passion } & \multirow[b]{2}{*}{ ESCAPE } & \multicolumn{4}{|c|}{ Motives } \\
\hline & $\mathrm{HP}$ & $\mathrm{OP}$ & & SOCIAL & VICACH & AES & DRAMA \\
\hline \multicolumn{8}{|c|}{ Response to COVID-19 } \\
\hline Seriousness & $\begin{array}{c}.102^{*} \\
{[-.014, .219]}\end{array}$ & $\begin{array}{c}-.260 * * \\
{[-.371,-.144]}\end{array}$ & $\begin{array}{c}-.038 \\
{[-.144, .068]}\end{array}$ & $\begin{array}{c}-.058 \\
{[-.162, .055]}\end{array}$ & $\begin{array}{c}-.115^{*} \\
{[-.207,-.016]}\end{array}$ & $\begin{array}{c}-.019 \\
{[-.126, .094]}\end{array}$ & $\begin{array}{c}.081 \\
{[-.022, .185]}\end{array}$ \\
\hline $\begin{array}{l}\text { Behavioral } \\
\text { Responding }\end{array}$ & $\begin{array}{c}.213^{* *} \\
{[.121, .304]}\end{array}$ & $\begin{array}{c}-.211 * * \\
{[-.309,-.109]}\end{array}$ & $\begin{array}{c}.133 * * \\
{[.040, .223]}\end{array}$ & $\begin{array}{c}.125^{*} \\
{[.020, .230]}\end{array}$ & $\begin{array}{c}.167 * * \\
{[.074, .263]}\end{array}$ & $\begin{array}{c}.117^{*} \\
{[.019, .216]}\end{array}$ & $\begin{array}{c}.224 * * \\
{[.121, .326]}\end{array}$ \\
\hline COVID-19 Worry & $\begin{array}{c}-.035 \\
{[-.137, .070]}\end{array}$ & $\begin{array}{c}.199 * * \\
{[.104, .292]} \\
\end{array}$ & $\begin{array}{c}.268 * * \\
{[.158, .368]}\end{array}$ & $\begin{array}{c}.092 \\
{[-.024, .203]}\end{array}$ & $\begin{array}{c}.136 * * \\
{[.032, .236]}\end{array}$ & $\begin{array}{c}.026 \\
{[-.085, .138]}\end{array}$ & $\begin{array}{c}-.026 \\
{[-.129, .077]}\end{array}$ \\
\hline
\end{tabular}

Note. $N=395$. Partial correlations are presented with passion types (controlling for the other passion type). Correlations are presented with fan motives. Confidence intervals reported in brackets are bias-corrected and based on 5,000 bootstrap samples. All items assessing responses to COVID-19 are reported in Table S4 and were answered on a scale from 1 (not agree at all) to 7 (totally agree) . HP = harmonious passion. $\mathrm{OP}=$ obsessive passion. $\mathrm{SOCIAL}=$ social interaction. VICACH $=$ vicarious achievement. AES $=$ aesthetics. $* p \leq .05, * * p \leq .01$ (two-tailed). 


\section{Additional Notes on the Mediation Model}

The mediation model was tested in Mplus (version 8) using robust maximum likelihood estimation (MLR). The four threat appraisal items from the Stress Appraisal Measure (Peacock \& Wong, 1990) were specified as indicators of threat appraisal, specific subscales of the brief COPE (Carver, 1997) were specified as indicators of disengagement (denial, disengagement, venting) and emotion-focused coping (emotional support, religion, positive reframing), and the following pairs of items from the Passion Scale (Vallerand, 2015) were averaged to create parcelled indicators for both HP and OP: item 3 and item 8 (HP1), item 6 and item 10 (HP2), item 1 and item 5 (HP3), item 11 and item 4 (OP1), item 2 and item 12 (OP2), and item 7 and item 9 (OP3). This model was identical to the model tested by Schellenberg and colleagues (2013).

A measurement model was first tested in which all latent variables were allowed to correlate. This model yielded the following fit indices: MLR $\chi^{2}=218.21(d f=94), p<.001$, $\mathrm{RMSEA}=.058,90 \% \mathrm{CI}[.048, .068], \mathrm{CFI}=.951, \mathrm{TLI}=.938$. Correlations between latent variables are reported in Table S3. The structural model, which we report in the main document and is displayed in Figure 1, yielded identical fit indices because the number of paths between factors was equivalent. Note that confidence intervals for indirect effects were bias-corrected and based on 5,000 bootstrap samples. 